\title{
GENDER AND ONLINE DISCOURSE IN THE PRINCIPLES OF ECONOMICS
}

\author{
Duane B. Graddy \\ Department of Economics and Finance \\ Middle Tennessee State University \\ Murfreesboro, TN 37132 \\ Email: dgraddy@mtsu.edu
}

\begin{abstract}
Collaboration is the heart of online learning. Interaction among course participants brings excitement to the online environment and creates knowledge as a group activity. Impediments to active collaboration reduce group, as well as individual, potentialities. Past studies of online discussions have found differences in the style of female and male conversations that could impede the learning process. The conversational styles of female and male students in two online principles of economics classes were analyzed in the present study. The null hypothesis posited no difference in the styles of online discourse between female and male students. The null hypothesis was rejected, implying gender differences in conversational styles. The tone of male postings was more optimistic than the tone of female postings. Female conversations used words revealing social isolation and the rejection of social norms. The paper also discussed the issue of the male $\mathrm{X}$-factor in the principles of economics from a sociolinguistic perspective.
\end{abstract}

\section{KEYWORDS}

Collaborative learning, learning effectiveness, computer-mediated communications, gender differences, distance learning

\section{INTRODUCTION}

The performance of students in online principles of economics courses has been examined in a few recent papers. The studies most directly related to the present work are those of Coates and Humphrey [1], Manning [2], and Navarro and Shoemaker [3]. All of these papers addressed the performance of students in blended principles of economics courses. Coates and Humphrey examined the relationship between postings to the class bulletin board and student performance on quizzes and exams [1]. Their statistical analysis showed that student postings to the class discussion board were positively associated with higher final exam scores. Lurking on the discussion board did not have the same effect. The coefficient for passive reading of posts was not statistically significant. Manning discussed the use of e-mail and discussion lists in principles of economics course [2]. The essence of the paper was that computermediated communication facilitated student-to-teacher, teacher-to-student, and peer-to-peer interactions, with the implication that increased discourse improved learning outcomes. The evidence, while informative, was anecdotal, as it was based on a narrative of the author's classroom experiences. Navarro and Shoemaker reported similar findings. Students with access to online communications, such as bulletin boards, chat rooms and e-mail, scored significantly higher on exams than those students without such access [3]. 
If participation in online discussions improves student performance, then it is very important that students have equal access to the benefits of this interactive forum. However, studies of computer-mediated communications in other disciplines suggest differences in the style of discourse between women and men that could alter the distribution of benefits among course participants [4, 5, 6, 7, 8, 9, 10, 11, 12].

Herring concluded that gender socialization from face-to-face interactions is carried over into the asynchronous environment $[7,8,9,10]$. She found the male conversational style to be adversarial, selfpromoting, contentious, and assertive. Males were less concerned about discussion posting rules than females, and males worried more about threats to individual expression. In addition, Herring found that males were likely to post longer and more frequent messages than their female counterparts. Female computer-mediated conversations tended to be qualifying, apologetic, supportive, and polite. Furthermore, in mixed-gender open discussions, females posted fewer messages and were less likely to persist when their messages received no response. Women seemed to participate more actively in situations where an individual (teacher/facilitator) maintained order and group focus. This higher participation rate held for online courses even when the facilitator was male. Herring concluded that women succeed in online discussions when the environment was civil and free from threats and disruptions.

Other studies come to similar conclusions. Selfe and Meyer found that even under conditions of anonymity, males who enjoyed high status off-line dominated the interactions of an academic listserv [13]. Rossetti related the differences in online discourse between females and males to a peer socialization process that begins in early childhood [11]. In the formative stages of social development, children tend to associate with individuals of the same gender. This socialization process results in distinctive ways of creating rapport and negotiating status within the gender groups. According to Rossetti, females are collaboration-oriented, using language to negotiate closeness as a basis for establishing friendships. In contrast, males negotiate their status within the group through a competition-oriented style of discourse.

Tannen indicated that "girls tend to learn conversational rituals that focus on the rapport dimension of relationships, whereas boys tend to learn rituals that focus on the status dimension" [14]. Burkett attributed the differences in language styles between genders to significant differences in the biological structures of the brains of men and women [4]. At a molecular level, studies find gender differences in neuronal density, connectivity, and synaptic biochemical reactivity. Burkett contrasted the assertive and egotistical language of males to the supportive and attenuated style of females and concluded that brain structures and hormonal differences can explain the distinctive conversational styles.

Table 6 of Coates and Humphreys, revealed a positive and significant coefficient for the gender variable (male) [1]. The implication of this coefficient is that being male improved a student's score (raising the issue of the male premium [1] or male puzzle [15]) on the final examination. However, the authors did not test the interaction between the gender variable and the communications surrogates, in posting (bulletin board messages posted) and in reading (bulletin board post read). For instance, a positive interaction term would imply that males posted more messages than females, perhaps revealing a style of discourse uninviting to female participation. Style of discourse is not an issue of inherent verbal ability between the genders [16]. It relates to the learning environment and the potential for constructing knowledge within an online group. For example, if the linguistic patterns of females are less powerful than the style of males, then the online learning environment will reflect this fact.

Such an environment may be less conducive to learning by female students. For example, if, as was pointed out by Zhu, knowledge is created by a social presence (projecting one's personality through 
textual and linguistic means) in vertical (acknowledges a superior source) and/or horizontal (no authoritative source) interactions, then inhibiting or transmuting female conversations could disrupt the learning process for an individual and the entire group [17]. Open and reciprocal interactions among course participants can create a learning gestalt. However, subtle linguistic factors, which impede the inclusiveness and appeal of the interactions, can undermine the totality of the learning experience.

The present study posited that the degree of social presence is reflected in the language used by course participants. For example, words of isolation, disconnection, exclusion, self-sufficiency, and sequestration portend low social presence. In contrast, language indicating satisfaction, inspiration, cooperation, rapport, and commonality signifies greater salience of the participant in the social interaction.

\section{SAMPLE}

The sample for this study included 29 graduate students in two sections of an MBA prerequisite course focusing on the principles of economics. Females and males represented 58 percent and 42 percent of the sample, respectively. The students submitted a total of 75 messages during three online discussion sessions. All of the messages were included in the analysis.

The facilitator posted a specific question about a recent economic event to initiate the discussions. Students applied their knowledge of economic principles to explain the situation, to develop alternative strategies to resolve the issues, and to draw general conclusions from the specific scenario. The facilitator did not re-enter the discussion unless analytical impasses occurred, such as when students became bogged down on a technical point (for example in discussions of arc versus point elasticity or balanced budget multiplier).

Three discussions took place, two focusing on microeconomic topics and one directed to a macroeconomic event. The combined discussions represented twenty percent of a student's grade. The average course grade for the female cohort was below the average for males. The difference between the means was not statistically significant at the 5 percent level. However, it did reach significance at the 15 percent level.

The perspective of this paper differs from past works by focusing on the conversational traits of the participants. A fundamental aim of the paper was to determine whether the style of discourse between female and male students found in previous works was evident among the students in this study. For example, do the lexical scores indicate that males are more egocentric (individualistic, contentious) and females more communal (consensus building) in online academic discussions? If so, can any implications be drawn from these conversational styles about their potential impact on the learning environment in the online principles of economics courses?

$\mathrm{H}_{0}=$ no significant differences exist in the conversational traits of female and male students in the online discussions.

$\mathrm{H}_{1}=$ males and females have significantly different conversational traits in the online discussions.

The sample of MBA students provides a useful contrast to other studies. Samples from other studies are drawn from academic listservs, e-mails from groups ranging from bird watchers to vegetarians, undergraduate online courses, general electronic forums, the Linguist-L discussion list, and specialized 
computer conferences. MBA students are mature, career-oriented individuals with substantial work experience. All of the students in the sample were working at least 20 hours per week. They have F2F interaction with peers in business meetings and team projects on a regular basis. In addition, MBA students are screened for academic potential before being admitted to the program. These factors make the sample more homogeneous in terms of academic backgrounds and employment than many previous works. In these dimensions, the students are of similar social status. Hence, rejection of the null hypothesis for this sample would provide substantive evidence that the socialization process described in past studies is at work in online conversations $[7,8,9,10,11,18,19]$.

\section{METHODOLOGY}

Diction 5.0 [20] was used to analyze the tone of the online discussions. Diction 5.0 traces the words in the discussion postings, not the ideas, arguments, or political views. This lexically based software searches the content of online conversations for five semantic features (master variables) as well as 33 subfeatures. Each master variable is constructed using the 33 sub-features (dictionaries) according to a series of formulas incorporated into the software program. The master variable scores are constructed as $S_{m}=\sum_{i}^{n} a_{i}-\sum_{j}^{m} s_{j}$ where the $a_{\mathrm{i}}$ 's are additive subaltern traits and the $\mathrm{s}_{\mathrm{j}}$ 's are subtractive subaltern traits.

The online discussions are compared to 33 standard dictionaries and word lists in segments of 500 words. For discussions exceeding 500 words, the overall scores are the average of the individual 500-word segments.

The main lexical features (master variables) in Diction 5.0 are activity, certainty, commonality, optimism, and realism. Activity includes language-featuring movement, change, and avoidance of inertia. The subaltern features of the activity score are aggression, accomplishment, communications, motion, cognitive terms, passivity, and embellishment. Each subaltern trait represents a dictionary of categorical terms. Language expressing inflexibility, resoluteness, and determination are features of the certainty score. The determinants of this score include tenacity, leveling, collectives, insistence, numerical terms, ambivalence, self-reference, and variety. Commonality is language stressing shared values, group perception, and a rejection of egocentric modes of engagement. The components of this measure are centrality, cooperation, rapport, diversity, exclusion, and liberation. Optimism is language describing another individual, concept, activity, or event in a positive light. The component scores of praise, satisfaction, inspiration, blame, hardship, and denial are used to calculate the optimism measure. Language focusing on everyday events, practical issues (family, children, daily routine), and temporal references (day, now, time) is captured in the realism score. The elements of this score include familiarity, spatial awareness, temporal awareness, present concern, human interest, concreteness, past concern, and complexity.

The raw dictionary totals are converted to Z-scores (based on the mean values of the lexical scores of a predetermined community of discourse) and then added and subtracted according to a master variable's particular definition. For example, the commonality score (C) is calculated as the sum of the certainty $\left(\mathrm{z}_{\mathrm{c}}\right)$, cooperation $\left(\mathrm{z}_{\mathrm{co}}\right)$, and rapport $\left(\mathrm{z}_{\mathrm{r}}\right)$ sub-scores minus the sum of diversity $\left(\mathrm{z}_{\mathrm{d}}\right)$, exclusion $\left(\mathrm{z}_{\mathrm{e}}\right)$, and liberation $\left(\mathrm{z}_{\mathrm{l}}\right)$.

$\mathrm{C}=\Sigma\left(\mathrm{z}_{\mathrm{c}}+\mathrm{z}_{\mathrm{co}}+\mathrm{z}_{\mathrm{r}}\right)-\Sigma\left(\mathrm{z}_{\mathrm{d}}+\mathrm{z}_{\mathrm{e}}+\mathrm{z}_{\mathrm{l}}\right)$

According to Hart, each master variable is constructed from a thorough examination of the existing 
lexical research [20]. Whether a score is in or out of range is determined by comparing its magnitude to mean score for the predetermined community of discourse. In and out of range is used only when comparing the female and male traits to the community of discourse and when clarifying the signs of the trait coefficients. Diction 5.0 has 36 normative categories (communities of discourse) divided into seven individual classes and one general class.

The all cases community (general class) is composed of 22,000 English language documents both current and historical. Most of the data for the normative values are generated from a broad sampling of texts produced primarily in the United States between 1945 and 1998. Because of their analytical nature, the online discussions in this study are compared to texts in the problem-solving group. The problem-solving community of discourse includes seventy-five texts from group decision-making situations such as student peer mediations, teachers' caucuses, and project management issues.

The study proceeded in three steps. First, Diction 5.0 was used to derive a set of lexical scores for each student posting. This procedure produced a set of 38 attributes for each posting. The lexical scores are used to create an SPSS database. Each of the 75 messages with their 38 lexical attributes was coded as being posted by either a male (0) or female (1) student. The initial tests used descriptive statistics to characterize the conversational styles of male and female students. The descriptive analysis focused not only on statistical differences between the groups, but also on the magnitude of the effect size. Second, logit regression was used to estimate the probability that a particular posting was female or male. The probabilities are estimated from the individual postings. Finally, the results of the statistical tests are discussed in the context of past research on the male $X$-factor and its relationship to social presence in online discussions. The male X-factor is shorthand for the findings of past research that, with other factors held constant, portends that male students tend to perform better in principles of economics courses than female students [14, 15, 21, 22, 23, 24, 25].

\section{RESULTS}

This section explores the differences in female and male discussion postings by analyzing the mean lexical scores of the messages in the sample. Table 1 presents the lexical scores for the master variables classified by gender. Each master variable is discussed below in terms of its significant subaltern characteristics.

\begin{tabular}{|c|c|c|c|c|c|c|}
\hline \multirow[b]{2}{*}{ Lexical Scores } & \multicolumn{2}{|c|}{ Means } & \multicolumn{2}{|c|}{ Standard Error of Mean } & \multirow[b]{2}{*}{ t-statistic ${ }^{a}$} & \multirow[b]{2}{*}{ Significance } \\
\hline & Female & Male & Female & Male & & \\
\hline Activity & 51.972 & 42.771 & 0.575 & 4.293 & 2.124 & 0.042 \\
\hline Optimism & 49.739 & 52.462 & 0.528 & 0.605 & 3.319 & 0.001 \\
\hline Realism & 51.235 & 50.961 & 0.566 & 0.630 & 0.315 & 0.754 \\
\hline Commonality & 45.769 & 47.767 & 0.525 & 0.578 & 1.241 & 0.219 \\
\hline Certainty & 49.278 & 49.635 & 0.648 & 0.584 & 0.380 & 0.705 \\
\hline
\end{tabular}

\begin{tabular}{|l|c|l|c|c|}
\hline Lexical Scores & Cohen’s d & Cohen’s Effect Size & $\mathrm{r}$ & $\mathrm{r}_{\text {counternull }}$ \\
\hline Activity & $0.640^{\mathrm{b}}$ & Medium & 0.305 & 0.539 \\
\hline Optimism & $0.800^{\mathrm{b}}$ & Large & 0.371 & 0.625 \\
\hline Realism & 0.080 & Negligible & 0.040 & 0.080 \\
\hline Commonality & $0.300^{\mathrm{b}}$ & Small & 0.148 & 0.287 \\
\hline Certainty & 0.090 & Negligible & 0.045 & 0.090 \\
\hline
\end{tabular}


Table 1: Differences between the Means of Female and Male Lexical Scores

${ }^{a}$ With the exception of the activity score, Levene's test for equality of variances yielded insignificant F-values.

${ }^{\mathrm{b}}$ Significant at the $\alpha=.05$ based on an adjusted sample size of $\mathrm{n}^{\mathrm{a}}=2\left(\mathrm{n}_{1} \mathrm{n}_{2}\right) / \mathrm{n}_{1}+\mathrm{n}_{2}$.

${ }^{\mathrm{c}}$ Percentile standing is the standing of the average female posting relative to the average male posting. For example, a $\mathrm{d}=0$ implies the mean of the female group is at the $50^{\text {th }}$ percentile of the male group.

A $d=.8$ indicates that the upper half of the female scores exceeds 79 percent of the male scores. Nonoverlap is the percentage of nonoverlap of the female scores with those of the male scores. A d $=0$ means that the distribution of scores of the female group overlaps completely with the male group. A $d=.8$ indicates nonoverlap of $47.4 \%$ in the two distributions. Relative size of Cohen's d: negligible effect $(\geq-0.15$ and $<.15)$ small effect $(\geq .15$ and $<.40)$ medium effect $(\geq$. 40 and $<.75)$ large effect $(\geq .75$ and $<1.10)$ very large effect $(\geq 1.10$ and huge effect $>1.45)$. Tables for these statistics are included in [26], pp.21-23).

\section{A. Differences Between Group Means}

In these tests, the styles of female and male postings differ particularly in terms of activity and optimism. The mean activity score for females is significantly higher than the male score. The activity score features language indicating the avoidance of inertia. The Cohen $d$ (degree of departure from the null hypothesis) statistic indicates a difference in the means of about .5 of a standard deviation (medium effect size range). Gender classification explains about 9 percent (based on the point-biserial correlation between group membership and the activity scores) of the variability in the activity score. The $\mathrm{r}_{\text {counternull }}$ is the counternull value of the biserial $r$ that is as likely to occur at $p=0.05$ as the null, $r=0$ [36]. The true effect size of the activity measure is just as likely to be .54 as 0.0 , where .54 is the upper limit of the null-counternull confidence interval. While the activity score includes seven subaltern traits, only one is significantly $(t=2.694)$ different between the male and female postings: embellishment. That is, the difference between the means of the activity score is attributable to one subtractive feature. The mean embellishment scores for females and males were 0.0211 and 8.9845 , respectively.

Embellishment is a calculated score that measures the ratio of adjectives to verbs. Hart [20] developed this measure based on the idea that heavy modification bogs down a verbal passage making it less definitive of true action. Two traits account for the higher embellishment score among male postings. Males had a higher mean praise score $(\mathrm{t}=3.260 ; \mathrm{p}=0.002)$ and a lower mean present concern score $(\mathrm{t}=$ 1.748; $p=0.085)$. The $\mathrm{r}^{2}$, s for these scores are $0.127(\mathrm{~d}=0.78)$ and $0.04(\mathrm{~d}=0.42)$, respectively. Praise is a dictionary of adjectives that affirm some person (teacher or peers), group (classmates), or abstract entity (class or course). Praise encompasses adjectives expressing social qualities (delightful), physical qualities (powerful), intellectual qualities (reasonable), entrepreneurial qualities (successful, conscientious) and moral qualities (faithful). Present concern is a dictionary of present tense verbs indicating task performance (make, tell, bring, write, provide) and social operations (meet, govern, canvass). Both factors raise the male embellishment score, which in turn reduces the activity score.

The tone of male postings was more optimistic than that of females. The optimism score has a Cohen $\mathrm{d}$ in the large effect size range and an $r^{2}$ of 13.8. The $r_{\text {counternull }}$ for this measure is .625. Hart defines the optimism measure as "language endorsing some person, group, concept, or event, or highlighting their positive entailments" [27]. Optimism is language expressing a positive verbal tone. All three additive subaltern variables (praise, satisfaction, and inspiration) in the optimism measure are significantly higher for males than females. The differences between the means of the three subtractive variables (blame, hardship, and denial) are not significantly different from zero. The significance of the praise variable was discussed as a factor positively influencing embellishment. The satisfaction score $\left(t=2.074 ; r^{2}=0.056\right)$ includes words representing positive affective states (happy, cheerful, passionate) and experiences of joy and pleasure (celebrating, proud, encourage). Nouns denoting desirable personal (dedication, success, patience) and moral (truth, devotion, integrity) qualities comprise the inspiration dictionary. The 
difference between the mean inspiration scores is significant at the 0.005 level $(t=2.925)$. Group classification explains eleven percent of the difference in the mean inspiration scores.

Comparing the two groups to the problem-solving community of discourse reveals that female activity scores are in the high range, while their optimism scores are below the norm. Comparing the group norm to the female group produces an interesting result. The only subaltern variable that is significantly different is aggression. Female aggression scores are significantly above norm. Yet the scores are no different than those of the male group. Female praise and inspiration scores are below those of the community of discourse. Male activity scores are no different than the group norm. Their optimism scores are in the high range. Praise, satisfaction, and inspiration are in the high range as well.

Both groups have aggression scores above the community of discourse. Use of economic terminology raises the aggression scores. However, the difference between the group means of the activity score is not due to the aggression score. Female and male students differ on the use of adjectives to modify their verbal passages; particularly adjectives connoting praise and satisfaction. Optimism among males reflects positive language about the group, course, and the subject matter.

\section{B. Probability of Group Membership}

Table 2 reports the results of the logit analysis. In these tests the master variables are used to estimate the odds that a given posting is from a female or male student. The upper-portion of Table 2 lists the $\beta$ coefficients for the master variables. The null hypothesis is rejected for two of the coefficients: optimism and commonality. The negative signs of the coefficients indicate that larger values of these lexical scores are associated with smaller logits of gender. Higher optimism and commonality scores are predictors of male postings. Inclusion of these variables in the equation improves its predictive power over the null model. The likelihood ratio test yielded a $\chi^{2}(5)=18.853(\mathrm{p}=0.002)$. The Hosmer-Lemeshow test produced a $\chi^{2}(7)$ greater than the critical value at $\mathrm{p}=0.05(\mathrm{p}=0.426)$. Failure to reject the null hypothesis according to this test implies that the model's estimates fit the data at an acceptable level [28]. $\mathrm{e}^{\beta}$ shows the odds of a posting being classified as male or female for a given unit change in a lexical score.

\begin{tabular}{|c|c|c|c|c|c|c|c|}
\hline Lexical Score & $\beta$ & $\operatorname{SE}(\beta)$ & Wald $\chi^{2}$ & Df & \multicolumn{2}{|c|}{$\mathrm{p}$} & $\mathrm{e}^{\beta}$ \\
\hline Activity & 0.054 & 0.042 & 1.633 & 1 & \multicolumn{2}{|c|}{0.201} & 1.055 \\
\hline Optimism & -0.237 & 0.102 & 5.340 & 1 & \multicolumn{2}{|c|}{0.021} & 0.789 \\
\hline Reality & -0.080 & 0.088 & 0.836 & 1 & \multicolumn{2}{|c|}{0.360} & 0.923 \\
\hline Commonality & -0.187 & 0.093 & 4.072 & 1 & \multicolumn{2}{|c|}{0.044} & 0.829 \\
\hline Certainty & -0.009 & 0.077 & 0.014 & 1 & \multicolumn{2}{|c|}{0.905} & 0.991 \\
\hline Constant & 23.319 & 9.745 & 5.726 & 1 & \multicolumn{2}{|c|}{0.017} & NA \\
\hline Tests & $x^{2}$ & $\mathrm{df}$ & $\mathrm{P}$ & \multicolumn{4}{|c|}{ Classification Table } \\
\hline Likelihood ratio & 18.853 & 5 & 0.002 & & \multicolumn{2}{|c|}{ Predicted } & Percent \\
\hline Hosmer-Lemeshow & 7.031 & 7 & 0.426 & Observed & Male & Female & Correct \\
\hline Cox-Shell $\mathrm{R}^{2}$ & 0.222 & & & Male & 11 & 18 & 37.9 \\
\hline Nagelkerke $\mathrm{R}^{2}$ & 0.302 & & & Female & 5 & 41 & 89.1 \\
\hline McFadden $\mathrm{R}^{2}$ & 0.188 & & & Overall & & & 69.3 \\
\hline
\end{tabular}

Note: NA = not applicable

Table 2: Logit Regression Analysis of Female and Male Online Postings 
$\mathrm{e}^{\beta^{\prime}} \mathrm{s}<1$ are associated with decreases in the probability of being classified as female for a unit change in the lexical score. $\mathrm{e}^{\beta}$, $\mathrm{s}>1$ increase the odds of a posting being classified as female. For example, a oneunit increase in the optimism score is multiplied by 0.789; reducing the odds of the posting being classified as female by 22 percent. This result can also be expressed in terms of a reduction in the probability of being classified as female. The odds ratio for the null model is 1.586 which reflects the initial probability $(46 / 75=0.613)$ of being classified as female. As shown in Table 2, the odds ratio for the optimism score is 0.789 . Multiplying the odds ratio for the null model (1.586) by the optimism score yields an estimated odds of being classified as female of 1.251. This ratio translates into a new probability of being classified as female of 0.555 or a reduction of 10 percent. If the optimism score increases by 2 units, the $95 \%$ confidence internal for the probability of being classified as female would be 29 to .48 . The reduction due to a unit increase in the commonality score is 7 percent. For a 2 unit increase in the commonality score, the $95 \%$ confidence interval is .32 to .49 .

The lower right hand portion of Table 2 shows the classification result for the logit model. The predicted values of gender are listed in the columns while the rows are the actual gender totals. Eighty-nine percent of the female postings are correctly classified while 38 percent of the male postings are categorized properly. The total percentage classified correctly is somewhat better (69 percent versus 61 percent) than would occur from predicting group membership by using the most frequent category (female).

\section{DISCUSSION}

Collaboration among students in online discussions provides a forum for the social creation of knowledge. Cognitive engagement through social presence is the essence of the online learning gestalt. If social presence is lacking, interaction becomes anemic. Frustration, disappointment and disengagement can result. Several writers have argued that social presence is undermined by the marginalization of female conversation and by the natural tendencies of males to dominate online discussions. This observation seems to apply to voluntary discussion groups $[5,7,8,9,10,11,12,18]$ as well as more focused online classes [6, 29]. These studies postulate male conversations as assured, contentious, antagonistic, self- centered, and abstract. In contrast, female conversational styles are supportive, grouporiented, questioning, qualifying, and exhibit a concern for relationships. A corollary to this hypothesis is that because of these differences in conversational styles, social interaction in online discussions is circumscribed, putting females at a particular disadvantage in the online learning process. For example, Herring found women were more likely than men to react adversely to aggression in online conversation by falling silent (lurking only) and/or dropping out of the group [8]. She also discovered that women are less likely to persist in posting when their messages receive no responses.

The present study found differences in the conversational styles of male and female students in two principles of economics classes. Optimism was the key linguistic difference between the postings of female and male students. Males spoke with greater optimism than females. A unit increase in a posting's optimism score reduced its probability of being classified as female by 10 percent in comparison to the null model. The differences between the means of all three additive traits in the optimism formula differed significantly between male and female postings. Greater praise, satisfaction, and inspiration characterized male postings. None of the subtractive traits (blame, hardship, and denial) differed significantly between the two groups of postings. Males made greater use of words conveying positive affective states and terms connoting confidence in their social relationships. Females spoke with less enthusiasm and more present concern than males. In comparison to males, females used fewer adjectives of praise and more verbs expressing present concern. Both of these subaltern traits raised the activity score for female postings relative to males. A unit increase in the commonality score increases a posting's probability of being classified as male by 7 percent. While female postings use more words connoting the 
interaction among people, as predicted by past research, the group mean is reduced by the prevalence of terms (subtractives) expressing social isolation (self-sufficient, ostracize, discriminate), exclusion, and rejection of social convention (uninhibited, unencumbered, eccentric). To the extent that this language reveals a lack of social presence on the part of females, learning could be inhibited for them and the entire class.

These findings support the basic contention of the past studies that there are differences in conversational traits of male and female students in online discussions. Whether their corollary proposition follows is open to speculation. However, many studies do find what Anderson, Benjamin, and Fuss call the male premium, or what I refer to as the male X-factor, in the principles of economics course [21]. Anderson, et al. estimated that men obtained 2.5 to 3.5 percentage points higher grades and were less likely to drop the course than their female counterparts. After testing several hypotheses, they conclude that "several attempts to account for the male premium proved unsuccessful.”

As noted before, Coates and Humphrey [1] discovered a male premium on the final exam scores but failed to relate it to the participation in online discussions. Similar results were forthcoming from a study by Robb and Robb [15]. They discovered that female students fared worse in economics than males in spite of having better high school averages. Moreover, fewer women in their sample continued on in economics than did males. Coates and Humphrey were "unable to contribute to the explanation of the puzzle of female performance or continuation in economics through a role-model effect..."

Durr found that being male has a positive effect on exam performance in principles of macroeconomics courses [30].

Using a large sample of students from co-ed liberal arts colleges, Jensen and Owens concluded that males are more likely to major in economics, continue in economics courses, and less likely to be discouraged in first semester principles of economics courses [24]. In contrast, females expressed lower self-confidence in their ability to understand economics.

Ellis, Durden, and Gaynor studied the grading patterns in large sections of both macro and micro principles of economics courses [22]. In their study, the probability of a female making a D or F for any given number of absences is greater than for males. Earlier studies described similar findings for the gender variable [25, 26, 31, 32].

As discussed above, in comparison to female postings, the postings of male students show a higher degree of optimism. The optimism scores for male postings were, on average, significantly higher (greater than one standard deviation) than conversations in the problem-solving community of discourse. The praise, satisfaction, and inspiration scores exceeded the community norm as well. In contrast, female optimism scores were significantly below the community mean. Praise, satisfaction, and inspiration were more than one standard deviation below the community norm.

The commonality score (language highlighting agreed upon group values) for female postings was below the community average also. Terms reflecting social isolation and rejection of social convention were more prevalent in female postings than the average communication in the community of discourse. The low commonality score and indications of social isolation are surprising given that females represented more than half of the enrollment and 60 percent of postings. 
It should be remembered that these are mature students with similar academic backgrounds. Perhaps, as Herring points out, computer mediated conversations continue to reflect the gender hierarchy of F2F interactions [10]. In addition, economics as a subject may foster an air of the gender status quo, leading to the male $X$-factor in conversation, as well as other classroom attributes. As reiterated by May, the metaphor of the self-interested, self-directed "economic man" remains largely intact in the economics literature [33]. Males may identify more readily with this androcentric approach than females. For example, Tannen [18, p. 178], quoting Johnstone [34], describes the worldview of men as originating in an individual acting in opposition to other persons and natural forces. Men see life as a struggle to avoid the risk of failure. In contrast, women see the community as the source of power. Women struggle to gain acceptance into the community.

\section{CONCLUSIONS}

Online learning is fundamentally a social process. As a social process, it is predisposed to the patterns of off-line social interaction. Past empirical works contend that this outcome takes place $[4,5,6,7,8,9,10$, $11,12,18,19]$. According to these researchers, infusion of the gender hierarchy into online conversation impedes the flow of ideas and inhibits knowledge creation by truncating the discussions.

The present study analyzed the conversational traits of female and male students in two online principles of economics courses. Male discussion postings showed greater optimism and commonality than the postings of females. Measures of social isolation, exclusion, and rejection of social conventions are higher among female students than for the community norm or the cohort of male students. These stylistic traits do not exist in isolation but instead combine to form a view of female conversation that signals low social presence (affective interaction). The potential impact of low social presence is not only on the individual student but also on the knowledge formation capabilities of the group as a whole.

Recent findings by Richardson and Swan help to clarify these conclusions [35]. Their results show that students reporting higher perceived social presence (degree of salience of the person in the mediated interaction and the salience of the interpersonal relationship itself) also perceived that they learned more in the course. In addition, students who indicated higher social presence scores had higher levels (Likert scale) of perceived satisfaction. The conversational tone of isolation (high liberation and exclusion scores) and lack of optimism (low satisfaction and inspiration scores) among the female students in the current study indicated a lack of social presence [36, 17]. These results highlight the strategic role of the discussion facilitator (e-moderator) in identifying and overcoming subtle gender-based impediments to online learning in the principles of economics courses.

\section{REFERENCES}

1. Coates, D. and Humphrey, B. Evaluation of Computer-assisted Instruction in Principles of Economics. Educational Technology \& Society 4 (2): 1-16, 2001.

2. Manning, L. Economics on the Internet: Electronic Mail in the Classroom. Journal of Economic Education 27: 201-205, 1996.

3. Navarro, P. and Shoemaker, J. Economics in the Cyberspace: A Comparison Study (in press).

4. Burkett, R. The Biological Basis for Gender-based Difference in Web-based "Discussion” and Assessment. Paper presented at the Association for the Education of Teachers in Science, Costa Mesa, CA, 2001.

5. Carli, L. Gender Differences in Interaction Style and Influence. Journal of Personality and Social Psychology 56 (4): 565-576, 1989. 
6. Fahy, P. Use of Linguistic Qualifiers and Intensifiers in Computer Conferences. The American Journal of Distance Education 16 (1): 5-22, 2002.

7. Herring, S. Gender and Democracy in Computer-mediated Communication. Electronic Journal of Communication 3 (2): 1-16, 1993.

8. Herring, S. Gender Differences in Computer-mediated Communication: Bringing Familiar Baggage to the New Frontier. Paper presented at the American Library Association Annual Convention, Miami Florida, 1994.

9. Herring, S. Gender Differences in CMC: Findings and Implications. The CPSR Newsletter 18 (1): 112, 2000.

10. Herring, S. Gender and Power in Online Communications. CSI Working Paper (\#WP-01-05). Center for Social Informatics, Indiana University - Bloomington, 2001.

11. Rossetti, P. Gender Differences in E-mail Communications. The Internet TESL Journal 4 (7): 1-6, 1998.

12. Savicki, V., Lingenfelter, D. and Kelley M. Gender Language Style and Group Composition in Internet Discussion Groups. Journal of Computer-Mediated Communication 2 (3): 1-12, 1996.

13. Selfe, C. and Meyer P. Testing Claims for Online Conferences. Written Communications 8 (2): 163192, 1991.

14. Siegfried, J. and Fels, R. Research on Teaching College Economics: A survey. Journal of Economic Literature 17 (3): 923-969, 1979.

15. Robb, R. and Robb, A. Gender and the Study of Economics: The Role of the Instructor. Journal of Economic Education 30: 3-19, 1999.

16. Greene, B. Verbal Abilities, Gender, and the Introductory Economics Course: A New Look at Old Assumptions. Journal of Economic Education 28: 13-30, 1997.

17. Zhu, E. Meaning, Negotiation, Knowledge Construction, and Mentoring in Distance Learning Courses. Proceedings of Selected Research and Development Presentations at the 1996 National Convention of the Association for Educational Communications and Technology, ERIC documents: ED397849.

18. Singh, S. A Pilot Study on Gender Differences in Conversational Speech on Lexical Richness Measures. Literary and Linguistic Computing 16 (3): 251-264, 2001.

19. Tannen, D. You Just Don't Understand: Women and Men in Conversation. New York: William Morrow and Co., Inc, 1990.

20. Hart, R. Diction 5.0 (Version 5.0.01), 1999.

21. Anderson, G., Benjamin, D. and Fuss, M. The Determinants of Success in University Introductory Economics Courses. Journal of Economic Education 25 (2): 99-119, 1994.

22. Ellis, L., Durden, G. and Gaynor, P. Evidence on Factors That Influence the Probability of a Good Performance in the Principles of Economics, 1998. Retrieved September 6, 2003 from http://www.westga.edu/ bquest/1998/perform.html.

23. Greenlaws, S. and DeLoach, B. Critical thinking and Electronic Discussion. Journal of Economic Education 34 (1): 36-52, 2003.

24. Jensen, E. and A. Owen. Pedagogy, Student Gender, and Interest in Economics, 1996. Retrieved April 15, 2003 from http://www.hamilton.edu/acdemics/Econ/workpap/99 10pdf.

25. Lumsden, K. and Scott, A. The Economics Student Reexamined: Male-Female Differences in Comprehension. Journal of Economic Education 18 (4): 365-375, 1987.

26. Crowley, R. and Wilton, D. An Analysis of "Learning" in Introductory Economics. Canadian Journal of Economics 7 (4): 665-673, 1974.

27. Hart, R. Verbal Style and the Presidency: A Computer-Based Analysis. New York: Academic Press, 1984.

28. Peng, C., Lee, K. and Ingersoll, G. An Introduction to Logistic Regression Analysis and Reporting. The Journal of Educational Research 96 (1): 3-14, 2002.

29. McAllister, $\mathbf{C}$ and Ting, E. Analysis of Discussion Items by Males and Females in Online College Courses. Paper presented at the American Education Research Association, Seattle, WA, 2001. 
30. Durr, C. Factors Affecting Student Performance in Principles of Macroeconomics Courses, 1999. Retrieved September 6, 2003 from http://www.elon.edu/ipe/durr.pdf.

31. Heath, J. An Econometric Model of the Role of Gender in Economics Education. American Economic Association Papers and Proceedings, 226-230, 1989.

32. Myatt, A. and Waddell, C. Effectiveness of Teaching and Learning in Economics in High School. Journal of Economic Education 21: 355-363, 1990.

33. May, A. The Feminist Challenge to Economics. Challenge 45 (6): 1-19, 2002.

34. Johnstone, B. Community and Contests: How Men and Women Construct Worlds in Conversational Narratives. Paper presented at Women in America: Legacies of Race and Ethnicity, Georgetown University, Washington, DC, 1989.

35. Richardson, J. and Swan, K. Examining Social Presence in Online Courses in Relation to Students' Perceived Learning and Satisfaction. Journal of Asynchronous Learning Networks 7 (1): 2003.

36. Tu, C. The impact of Text-based CMC on Online Social Presence. The Journal of Interactive Online Learning 1 (2): 1-24, 2002.

\section{ACKNOWLEDGMENT}

The student data for this project is used with the approval of the Middle Tennessee State University Institutional Review Board under protocol number 02-021.

\section{ABOUT THE AUTHOR}

Dr. Duane B. Graddy received his M.A. and Ph.D. degrees in Economics from Lehigh University and his M.S. in Finance from the University of Tennessee. Dr. Graddy is on the faculty of the Department of Economics and Finance at Middle Tennessee State University and serves as the Director of Graduate Studies in Economics. He has been teaching distance education courses for ten years and participated as a faculty representative on Regents Online Degree Programs of the Tennessee Board of Regents. Dr. Graddy's research has appeared in the Journal of Interactive Learning Research, Journal of Finance, Journal of Financial Research, Journal of Business Finance and Accounting, Applied Economics, and Journal of Risk and Insurance.

Contact: Department of Economics and Finance, Middle Tennessee State University, Murfreesboro, TN 37132; Email: dgraddy@mtsu.edu 